\title{
Research on Protection and Utilization Strategies of cultural Resources in Traditional Villages of Tourism Development ${ }^{\star}$
}

\author{
Yiqing Luo ${ }^{1}$, Donghua Wang ${ }^{1}$ and Haiqiao Wen $^{1 *}$ \\ ${ }^{1}$ Civil Engineering And Architecture, Jiangxi Science \& Technology Normal University, Nanchang, Jiangxi, 330013, China
}

\begin{abstract}
Pailou Village which is the hometown of Song Yingxing, who is the author of Tien-kung $\mathrm{K}$ 'ai-wu, is taken as the research object in this paper. From the perspective of tourism development of traditional villages, the types of cultural resources in Pailou Village are summarized through combing the content of existing cultural resources. Then the value of its cultural resources is analyzed from three aspects: history and culture, art and society, tourism and economy. Therefore, the development path of the integration of culture and tourism is proposed, from five aspects of project positioning, industrial format, tourism planning, supporting facilities and smart tourism, the strategy of improving the tourism competitiveness of Pailou Village are summarized in this paper, which provides a theoretical reference for the sustainable development of traditional village tourism.
\end{abstract}

\section{Introduction}

Undertaking the essence of Chinese traditional culture, traditional villages are the non-renewable cultural heritage of farming civilization, the bond that maintains the cultural identity of Chinese descendants, as well as the foundation for the prosperity and development of national culture. In order to protect these traditional villages with a long heritage and rich characteristics and inherit Chinese traditional culture, China is constantly launching related policies. The rapid demise of traditional villages has been eased and the stage of protection, improvement and recovery has begun. Undertaking the essence of Chinese traditional culture, traditional villages are the non-renewable cultural heritage of farming civilization, the bond that maintains the cultural identity of Chinese descendants, as well as the foundation for the prosperity and development of national culture. In order to protect these traditional villages with a long heritage and rich characteristics and inherit Chinese traditional culture, China is constantly launching related policies. The rapid demise of traditional villages has been eased and the stage of protection, improvement and recovery has begun. Despite the rapid development of the protection of traditional villages, there are actually many difficulties and pain points in the course, which come from administrative obstacles and also from technical difficulties. Additionally, the repair and maintenance of traditional villages require huge amounts of funds. The source of the funds becomes the major problem for traditional village protection. The financial subsidies selected for the national traditional village protection list contributes only partially, while the majority still rely on society, especially tourism. The development of rural tourism has become a key source of funds for the protection of traditional villages.

In addition, most traditional villages have relatively fine natural environments, superior protection and cultural values to a certain extent, and the conditions and foundation for the development of tourism. Hence, to traditional villages with convenient transportation and close to towns, tourism development is one of the most valuable paths for their protection. It can make up for the lack of industries in traditional villages in the non-agricultural economic era, and promote traditional villages to open up a new path for the coordinated development of economy, society and environment. In recent years, some local governments have achieved positive results by developing tourism to protect traditional villages, however, there is also implementation embarrassment of traditional villages in practice. For instance, in the development of tourism, there have been mistakes such as demolishing old buildings for new buildings, demolishing real building for fake buildings, and excessive immigrating villagers. Therefore, traditional villages should develop tourism on the basis of the protection, discovery, and activation of the cultural connotation of the village, and prevent excessive commercial development, and promote the positive interaction between protection and development.

\footnotetext{
*Corresponding author's e-mail: jxhaiqiao@163.com
} 


\section{Analysis on the types and value of cultural resources in Pailou Village}

\subsection{Overview of Pailou Village}

Pailou Village belongs to Songbu Town, Fengxin County, Yichun City, Jiangxi Province, with $115^{\circ} 29^{\prime}$ east longitude and $28^{\circ} 43^{\prime}$ north latitude. It is only 600 meters away from the town center, 12 kilometers away from the county seat and 49 kilometers away from the provincial capital. It belongs to the one-hour economic circle of Nanchang, which has convenient transportation and obvious location advantages. In addition, the village is rich in cultural resources and has many existing historical environment elements. It was selected into the fourth batch of Chinese traditional village list in 2016. Its village protection work has also entered a new level. In the past three years, the main work of protection has been the rescue and restoration of some traditional buildings and the construction of infrastructure. The overall environment of the village has been improved, but the tourism development and promotion after protection has been stagnant. Therefore, under the premise of existing cultural resources, it is particularly urgent to explore the living protection path of tourism development in traditional village.

\subsection{Types of Cultural Resources in Pailou Village}

The name of the village reflects the natural and historical background of the formation of the village. Pailou Village is a village mainly inhabited by the Song family. For the Song family who live on farming, it is the basis for their survival and development to locate in the plain area close to the water source. Therefore, the village is adjacent to the Nanliao River in the north. In ancient times, the river was also called Yaxi, so the village was also called Yaxi Song Village. When it developed to the heyday of the Ming Dynasty, there were a large number of Jinshi and Juren in this village. Therefore, stone archways such as "Three Generations of Shangshu", "Fang Bodi", "Jinshidi" and "Shikefang" were built. This is nothing in other surrounding villages, so it was renamed Pailou Village.

\subsubsection{Natural resources.}

Generally, it refers to the surrounding environmental resources in the formation process of traditional villages[1], which is closely related to the pursuit of conforming to nature in the selection of village sites and the emphasis on Part-time Learning. Pailou village has been impacted and collapsed by floods in history. Therefore, when the descendants of the Song family moved and settled, they followed the principle of "close to water conservancy and avoid floods disaster" and chose to live on the fertile convex bank of the river, which can not only avoid flood but also expand the base[2], which provides natural conditions for farming. At the same time, the surrounding stream was used to excavate the foundation pond, so that the water around the village flowed around one place, so as to form a Fengshui pattern of surrounded by mountains and rivers, collecting wind and gas. In addition, the pond is shaped like a square inkstone, and the seven square inkstone pools are arranged like a jade belt, which expresses the expectation of the people of the Song family to "descendants can be officials". The paddy field outside the pond surrounds the village, showing an ecological landscape pattern of "mountain water field residence".

\subsubsection{Human resources.}

(1) Residential building. Pailou village is a flat-structure village, mainly residential buildings. There are 166 kinds of traditional buildings and remains in the village, accounting for more than half of the whole village. Among them, there are 9 immovable cultural relics registered (table 1), 3 historical buildings (table 2), and 154 traditional buildings.

Table 1. Statistics of registered immovable cultural relics in Pailou Village.

\begin{tabular}{ccccc}
\hline Name & Roadway & Construction Time & $\begin{array}{c}\text { Building } \\
\text { Area } / \mathrm{m}^{2}\end{array}$ & $\begin{array}{c}\text { Building } \\
\text { Coverage } / \mathrm{m}^{2}\end{array}$ \\
\hline $\begin{array}{c}\text { Three generations of } \\
\text { Shangshu gatehouse }\end{array}$ & Southwest of Mingpu Lane & Jiajing period of Ming Dynasty & 482.0 & 496.4 \\
Fangbodi gatehouse & West side of Jinshidi Lane & Longqing period of Ming Dynasty & 15 & 15 \\
Jinshidi gatehouse & West end of Jinshidi Lane & Chongzhen period of Ming Dynasty & 221.9 & 237.0 \\
Father\&Son house & South of Jinshidi Lane & Late Ming and early Qing Dynasty & 875.5 & 940.9 \\
Fangbodi house & West side of Jinshidi Lane & Late Ming and early Qing Dynasty & 585.8 & 585.8 \\
Mei Zhufang house & North side of Meizhu Lane & Qing Dynasty & 286.4 & 381.6 \\
Song Xindi house & North side of Jinshidi Lane & Qing Dynasty & 67.2 & 79.1 \\
Song Mingjing house & North side of Jinshidi Lane & Qing Dynasty & 281.0 & 552.5 \\
Song Mingpu house & North side of Jinshidi Lane & Qing Dynasty & 201.8 & 210.5 \\
\hline
\end{tabular}


Table 2. Statistics of historical buildings in Pailou Village.

\begin{tabular}{|c|c|c|c|c|}
\hline Name & Roadway & Construction Time & Building Area $/ \mathrm{m}^{2}$ & Building Coverage $/ \mathrm{m}^{2}$ \\
\hline Song Xianhuai house & Jinshidi Lane & Qing Dynast & 157.9 & 161.4 \\
\hline Song Mingpu house & Shangshudi Lane & Qing Dynast & 291.8 & 297.9 \\
\hline Song Xianzhong house & Jinshidi Lane & Qing Dynast & 179.7 & 186.3 \\
\hline
\end{tabular}

(2) Historical environmental elements. Historical environmental elements are material entities that have an important impact on the site selection and spatial pattern of villages. They are mostly marked by special natural places, ancient trees and human beings, reflecting human's respect for nature and social and cultural beliefs There are 28 historical environment elements in Pailou Village, including 1 historical slogan, 2 ancient tombs, 3 ancient wells, 4 gatehouses, 5 ancient trees and famous trees, 6 ancient lanes and 7 ponds (table 3 ).

Table 3. Statistics of historical environmental elements in Pailou Village.

\begin{tabular}{|c|c|c|c|c|}
\hline Category & No. & Name & Age of formation & Remarks \\
\hline \multirow{6}{*}{ Ancient lane } & 1 & Jinshidi lane & Qing Dynasty & \\
\hline & 2 & Menkoutang lane & Qing Dynasty & \\
\hline & 3 & Song mingpu lane & Qing Dynasty & \\
\hline & 4 & Song mingpu lane & Qing Dynasty & \\
\hline & 5 & Mingcheng lane & Qing Dynasty & \\
\hline & 6 & Meizhu lane & Qing Dynasty & \\
\hline \multirow{3}{*}{$\begin{array}{l}\text { Ancient } \\
\text { tomb }\end{array}$} & 7 & $\begin{array}{l}\text { Tomb of the first ancestor of the Song } \\
\text { family }\end{array}$ & Ming Dynasty & Renovated in 1992 \\
\hline & 8 & Tomb hill to the East & Ming Dynasty & $\begin{array}{l}\text { The burial ground of the } \\
\text { descendants of the Song family }\end{array}$ \\
\hline & 9 & Big pond & Qing Dynasty & Left \\
\hline \multirow{5}{*}{ Pond } & 10 & Small pond & Qing Dynasty & Left \\
\hline & 11 & Menkou pond & Qing Dynasty & \\
\hline & 12 & Big pond & Qing Dynasty & Right \\
\hline & 13 & Small pond & Qing Dynasty & Right \\
\hline & 14 & Lixing pond & Qing Dynasty & \\
\hline \multirow{5}{*}{ Gatehouse } & 15 & Mingcheng pond & Qing Dynasty & \\
\hline & 16 & Jinshidi gatehouse & $\begin{array}{l}\text { Chongzhen period of } \\
\text { Ming Dynasty }\end{array}$ & \\
\hline & 17 & Fangbodi gatehouse & $\begin{array}{l}\text { Longqing period of } \\
\text { Ming Dynasty }\end{array}$ & \\
\hline & 18 & Three generations of Shangshu gatehouse & $\begin{array}{l}\text { Jiajing period of Ming } \\
\text { Dynasty }\end{array}$ & \\
\hline & 19 & Ruiji Changgeng gatehouse & Qing Dynasty & Damaged \\
\hline \multirow{5}{*}{ Ancient tree } & 20 & Pagoda tree & Qing Dynasty & \\
\hline & 21 & Pagoda tree & Qing Dynasty & \\
\hline & 22 & Chinese tallow tree & Qing Dynasty & \\
\hline & 23 & Chinese tallow tree & Qing Dynasty & \\
\hline & 24 & Chinese tallow tree & Qing Dynasty & \\
\hline \multirow[t]{2}{*}{ Slogan } & 25 & Chairman Mao’s quotes & Since 1949 & C-39 residential exterior wall \\
\hline & 26 & Well beside Jinshidi gatehouse & Ming Dynasty & \\
\hline \multirow[t]{2}{*}{ Ancient well } & 27 & East side well of menkou pond & Qing Dynasty & \\
\hline & 28 & East side well of lixing pond & Qing Dynasty & \\
\hline
\end{tabular}

(3) Intangible cultural heritage. At present, the academia defines intangible cultural heritage in traditional villages as: folk literature, performing arts, traditional arts and crafts, traditional production knowledge, traditional life knowledge, traditional rituals, traditional festivals and other cultural matters preserved and inherited in traditional villages so far[3]. There are 5 intangible cultural heritages in Pailou Village, which are the making skills of rice cake, the making skills of
Huanglian mochi, the story of Song Yingxing and the "Tien-kung K'ai-wu", the making skills of slat-coated chicken, and the making skills of dilapidated powder.

\subsection{Analysis on the value of resources in Pailou Village}

Pailou Village regards a local settlement formed by blood relationship. The settlement tradition formed by 
the Song family in the village has cultivated the cultural landscape of local settlement based on the culture of farming-reading. The value of village resources is mainly reflected in three aspects:

\subsubsection{Historical and cultural value.}

Pailou Village was built in Yuan Dynasty and developed to its peak in Ming Dynasty, which was closely related to the imperial examination system at that time. According to records, in the late Ming and early Qing Dynasty, Pailou Village has formed the basic pattern of the village we see today. From the west side into the village, the three generations of Shangshu gatehouse, Gu's chastity gatehouse, Fangbodi gatehouse and Jinshidi gatehouse are arranged from south to north. There are four houses and Wangxiang tower in the village. In addition, there are father \& son house and Mogong incense, Qingong incense, Qifeng tower, chenpu house and so on. On the west side of the village, from south to north, there are three ancient bridges: Chenjia bridge, Zhongjian bridge, Xiabian bridge. Although they are no longer in existence, the village still retains the environmental composition, historical context and architectural tradition of its glorious period, which has high historical value.

As a village with farming as the main mode of production, influenced by the traditional Confucian and Taoist culture and the ancient imperial examination system, Pailou Village has many literati and scholars in history, and there are not a few officials. Song Yingxing, the author of "Tien-kung K'ai-wu", is the most famous. In addition, there are many other historical celebrities, including 48 Juren and 15 Jinshi of the Song family. Pailou Village accounts for more than two-thirds, and many people hold important positions. This is also the reason why there are many memorial gatehouses in Pailou Village, which has important cultural value for the study of Confucian thought of Part-time Learning.

\subsubsection{Art and social value.}

Most of the traditional buildings in Pailou Village are from the late Ming Dynasty to the early Qing Dynasty. They are typical courtyard style dwellings in Jiangxi Province, with patios as the core and halls and houses on all sides, forming a residential form closed to the outside and open to the inside. These traditional buildings still retain the wood-carved reliefs inlaid on doors and windows in the Ming and Qing Dynasty, which have high artistic value. Among them, the Father \& son house is the most complete. It is an official hall in Ming Dynasty, which is a courtyard with three depths and five bays. It covers an area of 850 square meters, the front is the guard hall, the middle is the official hall, and the back is the family hall. There are three halls, twelve patios and twenty-eight rooms. The halls are arranged longitudinally along the axis, separated by wooden partition fans, and connected by rooms and corridors. The eaves decoration, window decoration and hanging fence decoration in the hall are colorful and exquisite, which show the technology and the development of architectural form of the folk official architecture in Ming Dynasty, and provide rare material for the study of civil official architecture.

At the same time, as a single-surnamed blood settlement, the evolution history of Pailou Village is the development history of the Song family. According to the genealogy of the Song family, the Song family first lived near Yaxi. Because of the Yijing built at the begining of the Zhenguan period of Tang Dynasty, it was called the Song family of Yijing. Later, because of the flood in the Qingli period of Song Dynasty, they moved to the area of Liujia hill,which is today's Yaxi. According to records, the Song family has only been handed down to Yijing for two generations, while the Song family of Yaxi has been passed down for dozens of generations and has multiplied to this day. The Song family in Pailou Village is an important birthplace of the Song family in Fengxin County, and one of the important birthplaces of the Song family in the south of the Yangtze River, which has important social value for the study of the Song clan culture.

\subsection{Tourism and economic value.}

The rich natural resources, historical remains, cultural resources and non renewable attributes of traditional villages make them become potential characteristic tourism resources in the areas where traditional villages are located[4]. As mentioned above, Pailou Village has obvious location advantages and rich cultural resources, especially the tourism resources with the most local characteristics of historical and cultural celebrity song Yingxing. Therefore, the development of Pailou Village tourism has inherent resource advantages. At the same time, the villagers of Pailou Village have inherited the production skills passed down from generation to generation, especially the food production skills. If we can carry out sustainable redevelopment, combine it with industrial production, develop the local special products processing industry and rural catering service industry with local characteristics, to a certain extant, promote the improvement of traditional village infrastructure and increase the employment opportunities and income of villagers, in order to realize its economic value.

\section{Tourism development path and protection strategy of Pailou Village}

The development of rural tourism is one of the most effective ways to protect traditional villages. However, it will be devastating for traditional villages and their culture to blindly copy other local models and blindly turn traditional villages into scenic spots without combining with local reality. Therefore, in order to develop tourism in traditional villages, we must excavate local cultural resources, deeply integrate culture and tourism industry, improve the cultural creativity of tourism products, and create tourism industry with cultural connotation, so as to ensure the benign development of traditional village tourism. 


\subsection{Focus on project orientation}

Pailou Village emerged from the glorious career of Song Jing, the great ancestor of Song Yingxing. The Song family developed from an ordinary farming family to a renowned cultural family, which is a microcosm of traditional farming and reading culture. Therefore, to develop rural tourism, Pailou Village must build a distinctive brand, build a well-known rural tourism destination as the "Hometown of Song Yingxing", use historical celebrities as the label, take the Pailou story as the origin, the culture of farming and reading as the core, the landscape and farmland as the carrier, and local traditional skills as support, so as to create a traditional rural tourism village featuring agricultural cultural tourism and ecological agricultural landscape as the support.

\subsection{Innovation of industrial formats}

The current tourism products of Pailou Village are mainly sightseeing type, and the product type is single, which obviously are not suitable for the current trend of diversified development of rural tourism. What's more, its project positioning of traditional rural tourism village will definitely promote the integration of modern agriculture and tourism in Pailou Village. On the one hand, the agricultural resources and ecological advantages of Pailou Village can be well performed, sightseeing agriculture can be expanded from the original lotus pond to the entire rice field, rice and its derivative brands can be cultivated, farming experience tourism products can be developed, and a rural health homestay project can be built; On the other hand, relying on the content of the intangible cultural heritage of the village, to develop characteristic food, manufacturing, handicraft and other local industries, and cultivate family workshops, handicraft workshops, and rural workshops. To adapt to the new changes in the diverse needs of the market, and promote the transformation of traditional village industries from a production-oriented single format to a market-oriented new format of diverse and integrated development.

\subsection{Tourism planning and design}

Comprehensively considering the needs of protection and continued development, the overall spatial function structure of Pailou Village is sorted into "one axis, one belt, and five districts".

(1) One axis: Taking the old Pailou Village's core doorway as the boundary, the traditional village core protection area of Pailou Village is divided into two core spaces, the farming culture exhibition area and the folk culture experience area.

(2) One belt: To create a waterfront landscape belt along the Qifang Pond at the entrance of the village to enrich the external spatial interface of the village.

(3) Five districts: to make full use of the natural and cultural landscapes of the village, and divide the overall space of the village into five major areas: ecological agriculture viewing area, farming and reading culture display area, folk culture experience area, rural health living area, and planting agricultural experience area ,so as to maximize resources utilization.

The external environment of the village is mainly based on the ecological agriculture viewing area and planting agricultural experience area. On the basis of the original lotus pond, the existing farmland resources are integrated, the ornamental farmland landscape is designed according to the growth law of crops, and a certain area of planting agricultural experience area along the village boundary is planned, according to the growth cycle and law of the crops, the farming culture and art festival is held, and the interpretation of the era of "farming" in the farming culture is strengthened through cultural creativity.

The traditional village core protection area takes the father \& son house as the core, together with the surrounding immovable cultural relics and historical buildings, they construct a farming cultural area, which collectively displays the farming cultural history and physical evidence of Pailou Village; At the same time, the barren site of the core protection area is cleared and built into a public activity square in the village to carry various folk activities in the village. Taking the advantage of Meizhufangju, a folk culture museum is set up, and a folk culture street along the famous shop lanes is built, to use the buildings along the street or transform them into handicraft workshops to display the production technology and process of the food intangible cultural heritage of Pailou Village.

In addition, in the traditional style of the village, the idle residential buildings or the farmers' own houses are transformed and developed into homestays to form a rural health residential area, especially the residential buildings on the border of the village can be combined with rice fields to form a culturally creative homestay product.

\subsection{Improve supporting facilities}

As mentioned above, the protection work of Pailou Village over the past three years concentrated on the rescue repair work and infrastructure construction of some traditional buildings, which has provided basic guarantee for the development of tourism. In addition, specific layouts should be made in the four aspects of tourism accommodation, catering services, entertainment facilities and auxiliary facilities in combination with industrial development. In regards to construction of accommodation facilities combined with tourism planning, the government should uniformly guide local residents to transform their own houses, especially vacant residential buildings, and freely combine with bookstores, workshops, museums and other formats through cross-border cooperation to form a rich life experience space and improve the quality of accommodation.

In terms of catering services, the village's intangible cultural heritage: rice noodles, Huanglian glutinous rice, salt-packed chicken, diezi noodles and other foods are 
the main contents to promote the effective inheritance of intangible cultural heritage; in terms of entertainment facilities, the focus should be on "farming" of village farming and reading culture to create a farming project with strong participation and experience, which allows tourists to experience the whole process of food from planting and maturity to local traditional food; as for auxiliary facilities, except for the construction of basic hardware facilities, software facilities should also be perfected and upgraded to fully realize rural tourism informatization.

\subsection{Build smart tourism}

Smart tourism is an advanced stage of tourism informatization development and an important means to promote the transformation and upgrading of rural tourism[5]. Rural tourism in the information age should take advantage of the Internet. The first step is to complete the construction of traditional village digital museums, and use text, audio, video, pictures, panoramic views, and virtual reality to fully display the cultural resources of the village. The second step is to further integrate the idle resources of offline traditional villages, strengthen brand building, and transform the main crops (such as rice, kudzu, lotus) in Pailou Village into tourism products, and make it an important carrier for the combination of agriculture and tourism, which shall then broaden income channels for local farmers. The final step is to strengthen digital empowerment and online promotion, transform traditional management and marketing models, build a smart tourism management platform, enhance functions such as online publicity, consultation, booking and payment, strengthen the interactive experience of tourists, and realize intelligent marketing, management and service.

\section{Conclusion}

Traditional village is an important carrier of agricultural civilization in China, but in the pursuit of economic benefits of modern society has lost the realistic basis for survival, there is no absolute protection of development can only be empty talk. The development of tourism is an effective way to protect traditional villages and a special way to modernize traditional villages. However, if we want to take the road of tourism development well, we must base on the cultural connotation of traditional village and give full play to the historical, cultural, artistic, social and economic values of traditional village. Through in-depth excavation of traditional village cultural resources, integration of resource types, establishment of tourism brand, creation of diversified industrial formats, and full display of its traditional culture. This is not only the important purpose of the protection and development of traditional village, but also the characteristics that can make tourism development more competitive and attractive.

\section{Acknowledgement}

* The financial support from the Fundamental Research Funds is Jiangxi Provincial Cultural and Art Science Planning Project YG2018132 and the Innovative Training Program for College Students of Jiangxi Science \& Technology Normal University 20201404070.

\section{References}

1. Wang, H., Xu L. (2017) Research on the protection and development of traditional village cultural resources under the background of ecological civilization construction. Northern Economy., 8:73-76.

2. Wang, J., Wang, J. (2005) The Relationship between the Choice of Village Location and Geomantic Pattern in Ancient Chinese Agricultural Society. Xi. An Univ. Of Arch. \& Tech. (Social Science Edition).,24(3): 17-21.

3. Li, Y. (2018) How to keep our nostalgia in the protection of intangible cultural heritage in traditional villages. China Social Science Journal.,6: 8-19.

4. Xia, Z.Q. (2015) The value and sustainable development of Chinese traditional villages. Journal of Fujian Provincial Party School of CPC., 10: 62-67.

5. Yang, S., Fang, C.Y., Yan, X., Wang, J. (2018) Study on the construction of smart rural tourism in Jiangxi Province. Journal of Cooperative Economy and Science \& technology.,5: 8-10. 